\title{
SCHIZOPHRENIA SYMPTOMS ACUTE IN TEDDY ALIAS ANDREW IN THE "SHUTTER ISLAND” NOVEL BY DENNIS LEHANE
}

\author{
Elfi Rahmi ${ }^{1}$ \\ Universitas Putera Batam (UPB), Batam, Indonesia \\ Pb151210054@upbatam.ac.id \\ Tomi Arianto ${ }^{2}$ \\ Universitas Putera Batam (UPB), Batam, Indonesia \\ Tomi.arianto@puterabatam.ac.id
}

\begin{abstract}
This research discussed about schizophrenia symptoms in Teddy alias Andrew Laedis that was acute and dangerous and also discussed the psychodrama treatment for Andrew. The main character is described to have a dangerous illness which is schizophrenia due to get from his traumatic events in world of war. Some of traumatic event that Andrew is experienced actually like when Andrew killed hundred soldier during the war in Dachau, his guilt because he did not bring his wife, Dolores to psychiatrists then unpredictable his wife killed her three children and drowning her child in a pond and regret for the rest of his life who was forced to kill his beloved wife until die and he finally lost all his family. Andrew cannot escape from the reality and without unconsciously he became experiencing mental disorder. The fictional story written by Dennis Lehane (2003.This novel was using the theory of psychoanalysis approach by Sigmund Freud. By using the concept of Sigmund's theory this research examined the symptoms of acute schizophrenia in Teddy alias Andrew's character which showed that his id is more dominant than his ego and the superego did not almost non-existent. Andrew points out three types of self defense mechanisms, namely, denial projections, regression and displacement. Meanwhile, the process of psychiatric recovery treatment by Dr. Cawley is used a psychodrama.
\end{abstract}

Keywords: Schizophrenia, Delusion, Hallucination, Psychoanalysis Approach, and Psychodrama.

\section{INTRODUCTION}

In human life, people usually have dark experiences live. The dark past events can make people experience psychological disorders caused by deep trauma. Trauma usually will appear when people having certain emotional injuries. Such as the deep traumatic related with world of war, rape, murder and etc.

However, deep trauma in every people has different effect even though the trauma is the same case. For example death can make someone traumatic, but 
not for other people. The condition such as death usually will happen to everyone but the mechanism psychology actually difference. Every human has a distinct defense mechanism. In facing the trauma, human should make a defense mechanism to accept the reality live and remembering all the dark memories that may naturally go away. For some of cases in reality, human cannot accept to much pain in their live so that can make them to be broken and this condition continued to be a big problem in human psychology. Some of people will suffered deep trauma and some of them having a mental disorder.

According to Cubukcu (2012) trauma has some bad effect which is affected human's individually which can create a new identity in human mind and this condition make them has different perception to other people, finally this condition create to mental illness or mental disorder. As people known in previous era, one of the example about the mental disorders that always happen after the world of war is schizophrenia. According to Mueser and McGurk that quoted by Amriani (2017) said that Schizophrenia is one of a serious psychological disorder that can marked or identified by the symptoms such as delusions, hallucinations, and loss of contact with reality, disorganized speech and move, nightmare, amnesia, heard the sounds, social withdrawal, and depression. It means that schizophrenia was very dangerous for human because the effect schizophrenia can damage human identity and un-control by themselves.

The issue of schizophrenia symptoms can analysis in literary works, such as novels, movie or drama. The researcher found one of the novel that described a character who has dark experience related with schizophrenic symptoms in the Shutter Island novel. This novel written by Dennis Lehane and published in 2003. This novel told about a man named Teddy Daniel alias Andrew Laeddis. He is a patient in Ashecliffe hospital for the criminally psychology and dangerous man. In the story told that Andrew is a veteran U.S marshal in World War II who became getting a mental disorder because he has some traumatic events after the war in Dachau. There were some main events those to be traumatic and brought him to indicated his schizophrenia symptoms and became delusional acute. The events that make Andrew felt guilt. This novel actually followed how Andrew's 
delusional acute in his mind as the result from his traumatic memories that was too much painful to be remembered by him. This condition make him always has hallucination and has delusional acute which is identified as the schizophrenia symptoms.

Then the result of his illness made him could not able to face the reality. In Andrew's mind created a new identity as Edward Teddy Daniel who as a detective that come to shutter island with the big mission to find the patient number 67 . He came with his partner Chuck Aule who actually his psychiatry during in hospital.

The researcher analyzed the schizophrenia symptoms in Shutter Island novel by using a psychological approach by Sigmund. The reason to analysis this novel because to want more deep about the schizophrenia in Andrew character and treatment to make him recovery or not from his experience.

\section{THEORY OF THE RESEARCH}

In English literature, the researcher need theory to make it this research to be obviously. As people known, the term of psychoanalysis theory firstly made by Sigmund Freud in 1896. Freud formulated some of distinct description about the psychoanalysis as one of the procedure to investigate the mental illness.

Some of the psychoanalysts said that one of the basic principles of psychoanalysis was a deep traumatic experience. It was happening when a person experiencing one of painful accident that cannot forget in their mind for a long time and bad condition.

2.1. Freud's Structure of Personality

According to Freud (1937) said that in human mind has three part of the mind which were conscious, subconscious and unconscious. All activities that create in human mind can determine and influence of human personality. In Freud's theory of personality. $\mathrm{He}$ included this components there were id, ego, and the superego. $\mathrm{He}$ made the three terms for more easy understanding about personality works and how the mental disorder may develop by the indication illness.

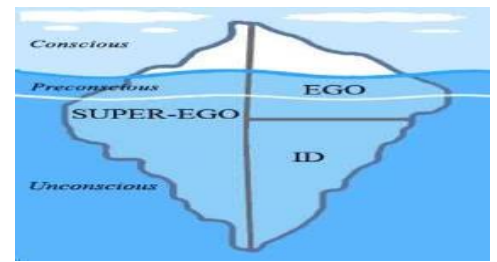

Figure 1: Structure of Personality According to Duane (2017) the first basic in human personality was id, which has big encouragement to operate human 
unconscious mind. So it means that the id was a basic desire that human has as long they lived.

The ego related with human rational in the human's personality which people conscious with their action. The ego aimed to help the id to get satisfying and desire but still but still consider to make differences between fictive and reality. So ego determined which need that should be more priority or not.

The superego included the moral values and something that was learned in family, social and culture. The function of human superego to control of human id's desires which were forbidden in society and to make the human ego performed in accordance with accepted values.

People known that the id, ego, and the superego should work to get harmony. But the human ego usually more weak than human's id. Freud explained that whenever human mind made some trouble, there were three parts of the mind appeared and psychological problems would be happen. Freud informed that human should have apply their defense mechanisms.

\subsubsection{Defense Mechanisms}

According to Grohol (2016) defense mechanisms is human ego which operated with unconscious condition level. This mechanism sight with feeling, and when individual felt unpleasant. Defense mechanism attempt to cope with traumatic memories, mental disorder, depressed or stress to help made a better feeling for the personality. According to Freud (2013) defense mechanism divided into some of part such as below:

\section{a. Denial}

Denial is one of process defense to refuse something that unpleasant to accept the real situation. Denial generally can be seen when people tried to avoid acknowledging painful feelings, or trauma that had been happen. As Anna (1937) said that denial can operate in unconscious thought which involves to block the external condition from conscious. If the some situation was really difficult to handle by themselves, the person would refuse to accept facing the truth.

b. Displacement

According to Freud (1933) displacement is the transfer of impulses, thoughts, and feelings (usually aggression) to helpless objects or substitutes. The use of displacement usually happens when a person could not express their feelings directly to the person who has a problem with him. By using displacement, people moved their emotions into destructive activities and they tend to be expressed negatively. 
c. Sublimation

Anna (1937) said that sublimation has some similarities with displacement but it would be only happen when people managed to move their emotions into positive thinking and beneficial actions rather than destructive activities.

d. Regression

According to Grohol (2016) regression is a reversal to the initial stages of development to make the establishment of impulses or thoughts unacceptable. When people troubled or scared then they would act like children rather than acting as they should.

\subsubsection{Schizophrenia}

NIMH Stated that schizophrenia is one of a serious mental disorder that influence how people perception, thought, feeling and behavior. According to Freud (1933) said that usually normal people have the big power to control their instincts exactly id, ego and the superego. Thus schizophrenia happened when the ego did not have the big power to control the instincts of human id. So, Freud explained schizophrenia as a regression process to continue the next level that people called as frustration or stress, and usually has some conflict with other people around him.
Freud said that the symptoms of schizophrenia developed from two processes. First regression to the pre-ego stage; and efforts to rebuild ego control. He had been propose that when human world was in very difficult situation, people would be develop schizophrenia from their experience then back to the earliest point in their development.

a. Schizophrenia

NIMH said that schizophrenia symptoms divided into three categories:

1) Positive Symptoms

a. Hallucinations

According to Telles-correia, Moreira, \& Gonçalves (2015) said that Schizophrenia symptoms can be identify if people has hallucinations and has symptoms in their sees, hears, smells, tastes, or feeling things that they did not have to make different with the reality or fictive. In common people with schizophrenia acute who hear some voices by themselves for a long time because they has problem or traumatic in their live such as traumatic when lost family, friends and love.

b. Delusions

According to Kiran \& Chaudhury (2017) a delusion is something that obviously false or wrong in mind when a person cannot divide the true or fictive 
and indicates an abnormality in influenced person's content of thought. Some people believed that they always were in dangerous situation and some of people were trying want to hurt them but actually did not. The specific characteristic in delusion can be identified when a person always true with their action, word, confidence and believed with their opinion without think what other people said.

c. Thought Disorder

According to Hart \& Lewine (2018) explained that thought disorder is a phenomenon that connected with human thinking which were correlation with communication, ability to speak and how to respond the information from others. People with thought disorders usually have some trouble in their mind. Sometimes they would stop to talk in the middle and speak again without meaning or worse word in their utterance.

B. Schizophrenia Treatments

a. Psychodrama

According to Cruz, Sales, Alves, \& Moita (2018) said that the original theory about psychodrama first purposed by Moreno in 1921 and then developed by some authors. The psychodrama in literature has a context and application that unclear but in doctor medication the technique of psychodrama can use for treatment patients that has schizophrenia symptoms acute. This technique developed with therapy and intensive treatment.

b. Medication

(Psychopharmacology)

According to Cruz, Sales, Alves, \& Moita (2018) also said that medication or psychopharmacology actually was one of old or long treatment that used for treat people which has mental illness, psychology disorder and other mental disorder. However, the medication in the last time has some weakness and did not effective to treat the patients then some psychiatrists choose to develop other treatments than using the medicine.

\subsection{Previous Studies}

In this research, the researcher found the research about schizophrenia by international journal and national journal. The first international journal was written by Fang, Chen, Wang, Ren, \& Zhang (2019) entitled "Progress in depressive symptoms in schizophrenia patients : A possible relationship between SIRT1 and BDNF". This research analyzed about Depressive symptoms that identified as a schizophrenia, they was made some research to identify the patient that has 
positive mental illness with use the evaluation method PANSS and RBANS to know the percentage the schizophrenia symptoms.

The second international journal was written by Watkins, John, Bradshaw, Jones, \& Jones (2019) entitled "Schizophrenia in high risk opioid users : A short communication on an autopsy study". This research aimed to find the high risk in schizophrenia that always sure wider in some country such in United Kingdom. This research also did some investigation related with using drugs and the effect from drugs to human psychology. The similarities with previous research was using the same examine people that has schizophrenia. And the difference from the previous only in theory.

There were some national journal from Indonesia. The national journal written by Gofur (2015) entitled "Schizophrenia on the Main Character of The Shutter Island Film based on Sigmund Freud's Psychoanalysis Theory". This research aimed to know more deep that the main character has schizophrenia and analysis with psychoanalysis approach. Gofur's research analyzed the personality in Andrew's character that experiencing trauma and finally he is diagnosed has schizophrenia. The similarities with Gofur's research, the researcher use the object schizophrenia as the main point, and use the same theory by Sigmund Freud.

\section{METHOD OF ESEARCH}

In this research, the researcher used qualitative method. Qualitative method is a method that focused in explain data descriptively. According to Ratna (2015) explained that qualitative research is research contains natural data summarized in a literary work and involves elements of culture.

The object of this research is schizophrenia symptoms. The researcher was analyzed in a novel entitled schizophrenia symptoms acute in Teddy alias in the "shutter island" novel by Dennis Lehane.

In the process of collecting the data, the researcher used the method of observation and documentation study. According to Sudaryanto (2015) the method of observation is the method that used by the researcher to find the data by observation. Then, researcher used non-participatory in analysing the novel.

After collecting all the data, then it arranged systematically to analyze the data. There were several steps already done to 
analyze data. First, check the data that has been collected. Second, compile and analyze data which then focuses on the research objectives. Third, make conclusions from the results of research in the form of analyzed data.

In the process analyzing the data, according to Ratna (2015), the method that used for analyzing the data has function to explain the indications between literary work and theory. Hence, another function is the ability to motivate or modify the idea of researcher. In this research, the researcher applied Freud's theory into shutter island novel.

After doing the analysis data, the next step is presenting the result of analysis. In this research, the researcher present the result in informal ways.

\section{DISCUSSION RESULT}

AND

4.1. Andrew's Schizophrenia Describes Based on Novel

There were some traumatic events in Andrew Laedis in the past time. The events as the main point factors Andrew has schizophrenia that told detail in the novel Shutter Island. In this novel told that Andrew was an army and haunted during World War II in Dachau. The memory in Dachau cannot forget by him.
Andrew and other army really arrogant and brutal. Andrew always remembered when he shoot German soldier without any fight. The horrific Imagine never ever left from Andrew's mind. As the quotation below:

"How do you tell the wife and the parents and the kids that you've done this thing? You've executed unarmed people? You've killed boys? Boys with guns and uniforms, but boys just the same? Answer is-You can't tell 'em. They'll never understand. Because what you did was for the right reason. But what you did was also wrong. And you'll never wash it off." (Lehane, 2003, p. 135)

During the execution by American soldier in Dachau making some problems for the soldier personality. Such as Andrew Laedis who as a marshal that has mental illness after the war in German. He felt guilty after he shoot hundreds Nazi's soldier without thought the human being. He always felt the shadow of victim in the War appear in his mind. Andrew became alcoholic to press his depression that finally showing his id obviously.

The biggest problem in Andrew psychology when Dolores, his wife has bipolar 
disorder where her emotion did not consistent in long time. Andrew did not accept that his wife has a mental disorder and he did not bring his wife to psychiatry and the result Dolores killed her children. As the quotation below:

"She was suicidal. She hurt the children. You refused to see it. You thought she was weak. You told yourself sanity was a choice, and all she had to do was remember her responsibilities. To you. To the children. You drank, and your drinking got worse". (Lehane, 2003, p. 302)

Andrew still not accept the reality that his wife has mental illness. Here Andrew's id was more higher than his superego. It can be seen when he known that his wife would be dangerous for their children but he still ignore the reality. His id more dominant than the ego and superego. Andrew always refused to bring Dolores at doctor to treatment but never happen till finally the tragic occur:

"And Teddy screamed. He screamed so loudly that Dolores fell out of the swing and he jumped over her and jumped over the railing at the back of the gazebo and ran screaming, screaming no, screaming God, screaming please, screaming not my babies, screaming Jesus, screaming oh oh oh (Lehane, 2003, p. 323).

This story in the quotation above described the tragic and dramatic when Andrew should face the bad reality to see all his children die in a pond. $\mathrm{He}$ screamed loudly and jumped to the water. Andrew cried and again scream over. It so very sad. This accident finally brought the effect to Andrew psychology then he has schizophrenia acute. From the accident it can be conclude that some conflict, trauma and depression which is happen to him. It leaded him to create new identity in his mind as Teddy Daniel. This condition occurred when he cannot face the reality and all tragic memory in his mind.

4.2 The treatments of Teddy's Schizophrenia

In this research, the researcher divided two types of treatment for Andrew's schizophrenia in Shutter Island by Dennis Lehane. The first is psychodrama and medication:

4.2.1 Psychodrama

Andrew's schizophrenia followed his delusional story where he made fictive figure in his mind that has a role-playing. Dr. Cawley believed in modern era the psychological treatment had been create this method. Teddy's psychodrama alias 
Andrew Laedis treatment is set by Dr. Sheehan and Dr. Cawley who played the role as partner. The purposed of the psychodrama to realize that he thought all his fantasy and facilitate a patient to teach them directly about the truth. The quotation treatment psychodrama as below:

"Cawley, behind them, placed a record on the phonograph and the scratch of the needle was followed by stray pops and hisses that reminded Teddy of the phones, he'd tried to use. Then a balm of strings and piano replaced the hisses. (Lehane, 2003, p. 73)

Something classical, Teddy knew that much. Prussian. Reminding him of cafes overseas and a record of collection he'd seen in the office of a sub-commandant at Dachau, the man listening to it when he'd shot himself in the mouth. He was still alive when Teddy and four GIs entered the room." (Lehane, 2003, p. 73)

The psychodrama treatment is involving some people to play drama. It usually involved the music to treat them. From the music patient can feel the trauma which he remembered. It proved the psychodrama can use visual audio.
4.2.2 Medication

(Psychopharmacology)

Psychopharmacology was one long treatment to treat someone from the mental illness. The doctor usually will give patient to drink a drug. The aimed for this treatment was reduce the symptoms in any time. The medications not only used pill but also cigarettes. Like the quotation below:

"withdrawal from what?"

Teddy said." What did you give me?"

"Chlorpromazine. That's what you're on now. What you're withdrawing from. The same thing we've been giving you for the last two year." (Lehane, 2003, p. 291)

After Andrew took the cigarettes from Dr.Cawley, then Andrew felt like migraine. This condition make him to aftereffect in psychologically.

\section{CONCLUSION}

The novel Shutter Island written by Dennis Lehane in 2003. All of the story in his novel told about Andrew Laeddis as the main character who he has a schizophrenic acute. He always do something unconsciously which is developing from his delusions. The mental illness as the result of the traumatic 
experiences make him create a new character in his mind. Some events in the past that build his symptoms such as killing hundreds army in World War II, he ignored to take Dolores to the psychiatrist, but the most painful memory for him is the death of his family.

\section{REFERENCES}

Amriani, N. (2017). The schizophrenic in C.E Christiansen's "the roommate. Psychiatry Research Street, 87(9). https://doi.org/10.19044/esj. 2017.v13n23p310

Cruz, A., Sales, C. M. D., Alves, P., \& Moita, G. (2018). The core techniques of Morenian psychodrama: A systematic review of literature. Frontier in Psychology, 9(July), 111.

https://doi.org/10.3389/fpsyg .2018 .01263

Cubukcu, F. (2012). Effects of trauma in shutter island. Psychiatry Research, 4(9). https://doi.org/10.2019/apcu b73215072

Dennis Lehane. (2003). Shutter island. Unitad Kingdom: Bantam Press.

Duane, S. (2017). Theories of personality. Psychological Review, 86(9). https://doi.org/10.5406/amer jpsyc.126.2.0155
Fang, X., Chen, Y., Wang, Y., Ren, J., \& Zhang, C. (2019). Progress in depressive symptoms in schizophrenia patients: A possible relationship between SIRT1 and BDNF. Progress in Neuropsychopharmacology \& Biological Psychiatry, 95(June), 1-7. https://doi.org/10.1016/j.pnp bp. 2019.109673

Freud, Anna. (1937). Ego and the mechanisms of defense. London: karnac Books.

Freud, Sigmund. (1933). New introductory lectures on psychoanalysis. New York: Norton Books.

Gofur. (2015). Schizophrenia on the main character of the shutter island film based on Sigmund Freud's psychoanalysis theory. Psychological Science in the Public Street, 1(vii), 1-15. https://doi.org/10.1016/j.pai d.2015.01.086

Hart, M., \& Lewine, R. (2018). Rethinking thought disorder. Schizophrenia Bulletin Vol., 43(3), $1-10$. https://doi.org/10.1093/schb $\mathrm{ul} / \mathrm{sbx} 003$

Kiran, C., \& Chaudhury, S. (2017). Understanding delusions. Industrial Psychiatry Journal •, 18(1), 1-18.

https://doi.org/10.4103/0972 
$-6748.57851$

Lapsley, D. K., \& Stey, P. C. (2011). Id, ego, and superego. Encyclopedia of Human Behavior, 2nd Ed, 11(vii), 1-9. https://doi.org/DOI

10.1007/9988-3-319118yuan7

Ratna, N. K. (2015). Teori, Metode, dan Teknik Penelitian Sastra. Yogyakarta: Pustaka Pelajar. Sudaryanto. (2015). Metode dan aneka teknik analisis bahasa. Yogyakarta: Sanata Darma University Press.

Telles-correia, D., Moreira, A. L., \& Gonçalves, J. S. (2015). Hallucinations and related concepts - their conceptual. Frontier in Psychology, 6(July), 1-9. https://doi.org/10.3389/fpsyg .2015.00991

Watkins, A., John, A., Bradshaw, C., Jones, J., \& Jones, M. (2019). Schizophrenia in high risk opioid users : A short communication on an autopsy study. Psychiatry Research, 276(February), 112-114.

https://doi.org/10.1016/j.psy chres.2019.04.026 